\title{
DNase I Inhibits a Late Phase of Reactive Oxygen Species Production in Neutrophils
}

\author{
Daniela B. Munafo ${ }^{a} \quad$ Jennifer L. Johnson ${ }^{a} \quad$ Agnieszka A. Brzezinska ${ }^{a}$ \\ Beverly A. Ellis ${ }^{a}$ Malcolm R. Wood ${ }^{b}$ Sergio D. Catz ${ }^{a}$ \\ ${ }^{a}$ Division of Biochemistry, Department of Molecular and Experimental Medicine, and ${ }^{\mathrm{b}}$ Core Microscopy Facility, \\ The Scripps Research Institute, La Jolla, Calif., USA
}

\section{Key Words}

Neutrophil extracellular traps $\cdot$ NADPH oxidase $\cdot$

Myeloperoxidase $\cdot$ Exocytosis $\cdot$ Rab27 $\cdot$ Luminol $\cdot$

Isoluminol

\begin{abstract}
Neutrophils kill bacteria on extracellular complexes of DNA fibers and bactericidal proteins known as neutrophil extracellular traps (NETs). The NET composition and the bactericidal mechanisms they use are not fully understood. Here, we show that treatment with deoxyribonuclease (DNase I) impairs a late oxidative response elicited by Gram-positive and Gram-negative bacteria and also by phorbol ester. Isoluminol-dependent chemiluminescence elicited by opsonized Listeria monocytogenes-stimulated neutrophils was inhibited by DNase I, and the DNase inhibitory effect was also evident when phagocytosis was blocked, suggesting that DNase inhibits an extracellular mechanism of reactive oxygen species (ROS) generation. The DNase inhibitory effect was independent of actin polymerization. Phagocytosis and cell viability were not impaired by DNase I. Immunofluorescence analysis shows that myeloperoxidase is present on NETs. Furthermore, granular proteins were detected in NETs from Rab27adeficient neutrophils which have deficient exocytosis, suggesting that exocytosis and granular protein distribution on NETs proceed by independent mechanisms. NADPH oxidase
\end{abstract}

subunits were also detected on NETs, and the detection of extracellular trap-associated NADPH oxidase subunits was abolished by treatment with DNase I and dependent on cell stimulation. In vitro analyses demonstrate that MPO and NADPH oxidase activity are not directly inhibited by DNase I, suggesting that its effect on ROS production depends on NET disassembly. Altogether, our data suggest that inhibition of ROS production by microorganism-derived DNase would contribute to their ability to evade killing.

Copyright $\odot 2009$ S. Karger AG, Basel

\section{Introduction}

Human neutrophils constitute the first line of cellular defense against invading microorganisms. Upon contact with opsonized bacteria or fungi, neutrophils engulf microorganisms in a process known as phagocytosis. Neutrophils discharge the contents of their granules into the phagosome to form phagolysosomes. The bactericidal ability of these cells relies on the antimicrobial proteins and peptides that are released into the phagosome [1] and on their capacity to generate reactive oxygen species (ROS) [2]. The battery of microbicidal molecules includes proteins such as lactoferrin, lipocalin, lysozyme, elastase, gelatinase $\mathrm{B}$ and myeloperoxidase (MPO) along with bactericidal defensins. Despite the variety of antimicrobial

\section{KARGER}

(C) 2009 S. Karger AG, Basel

Fax +4161306 1234

E-Mail karger@karger.ch

www.karger.com
Accessible online at: www.karger.com/jin
Dr. Sergio D. Catz

Department of Molecular and Experimental Medicine

The Scripps Research Institute

10550 North Torrey Pines Road, La Jolla, CA 92037 (USA)

Tel. +1 858784 7932, Fax +1 858784 7981, E-Mail scatz@scripps.edu 
factors of neutrophils put into play, many microorganisms have the ability to escape phagocytosis-dependent killing using diverse mechanisms [for a review, see ref. 3]. These include the use of molecular barriers to evade recognition by the phagocytes, inhibition of trafficking involved in phagocytosis, prevention of the fusion of the phagosome with neutrophil granules and bacterial escape into the cytoplasm. To overcome these escape tactics, neutrophils have developed alternative tools to kill bacteria. For example, neutrophils can release the microbicidal components of their granules to kill microorganisms in the extracellular milieu. In recent years, it has become apparent that extracellular neutrophil microbicidal components can be regulated by a novel and sophisticated mechanism: the formation of organized extracellular DNA fibers containing histones and other proteins with bactericidal ability [4]. Microorganisms trapped in neutrophil extracellular traps (NETs) are killed by a mechanism that is poorly understood. The presence of proteins with bactericidal capacity, including histones, elastase and MPO, has been described in NETs and most likely contributes to the microorganism-killing process [4]. The importance of this mechanism is highlighted by the observation that microorganisms expressing deoxyribonuclease (DNase) evade NET-dependent killing [5].

The NADPH oxidase catalyzes the monoelectronic reduction of $\mathrm{O}_{2}$ to superoxide anion $\left(\mathrm{O}_{2}^{-}\right)$[6]. This multienzymatic complex produces highly reactive molecules whose oxidative capacity has been held in part responsible for the bactericidal ability of neutrophils. Patients with chronic granulomatous disease, whose NADPH oxidase is inactive, suffer recurrent bacterial and fungal infections [7]. The NADPH oxidase consists of the cytosolic factors $\mathrm{p} 47^{\text {phox }}$, p $67^{\text {phox }}$ and $\mathrm{p} 40^{\text {phox }}$, the membraneassociated cytochrome $b_{558}$ and the accessory proteins Rac2 and Rapla. In resting neutrophils, the oxidase remains unassembled and therefore inactive. In response to adequate stimuli, the cytosolic factor $\mathrm{p} 47^{\text {phox }}$ is phosphorylated in its carboxy terminus in what is considered a central event during NADPH oxidase activation [8-10]. Upon phosphorylation, the cytosolic factors are recruited to the membrane-associated cytochrome $b_{558}$, and the NADPH oxidase becomes assembled and active. The assembling of the NADPH oxidase can take place on the phagolysosome membrane [11], on the plasma membrane [12] or on the membrane of neutrophil granules [13], depending on the characteristics of the stimulus that initiates the activation process. MPO, a heme enzyme that utilizes NADPH oxidase-derived superoxide and $\mathrm{H}_{2} \mathrm{O}_{2}$ to produce microbicidal oxidants $[14,15]$, was proposed to localize on NETs [4]. In this report, we show that NADPH oxidase subunits and MPO localize on NETs, we show that ROS production is a DNase-sensitive process and we suggest a role for MPO-derived oxidants in NETdependent extracellular killing.

\section{Materials and Methods}

\section{Neutrophil Isolation}

Human neutrophils were isolated from normal donor blood by Ficoll density centrifugation as previously described [16].

\section{Human Subjects}

All procedures regarding human subjects have been reviewed and approved by the Human Subjects Committee at The Scripps Research Institute and were conducted in accordance with the requirements set forth by the mentioned Human Subjects Committee.

\section{Antibodies}

The monoclonal antibody raised against $\mathrm{p} 47^{\text {phox }}$ has been previously described [17]. The polyclonal antibodies against $\mathrm{p} 47^{\text {phox }}$ and $67^{\text {phox }}$ were raised against the carboxy terminal peptide STKRKLASAV and full-length p67phox, respectively, in rabbits. The polyclonal antibody anti-p22 $2^{\text {phox }}$ was described before [18]. The monoclonal antibody against CD11b was obtained from Calbiochem, San Diego, Calif., USA. The anti-MPO antibodies used in this work were goat anti-human from Santa Cruz Biotechnology (Santa Cruz, Calif., USA) and anti-mouse (Hycult Biotechnology, Uden, The Netherlands).

\section{Immunofluorescence}

Human neutrophils were seeded at $70 \%$ confluence in an 8-well-chambered coverglass (untreated or pretreated with polyL-lysine at $0.01 \%$ in PBS). In some cases, the neutrophils were activated with lipopolysaccharide (LPS; $100 \mathrm{ng} / \mathrm{ml}$ ), heat-killed Listeria monocytogenes (HKLM; $1 \times 10^{8} / \mathrm{ml}$ ) or phorbol-12myristate-13-acetate (PMA; $0.1-1 \mu \mathrm{g} / \mathrm{ml}$ ) for the indicated time at $37^{\circ} \mathrm{C}$ and then fixed with $3.7 \%$ paraformaldehyde, permeabilized with $0.01 \%$ saponin and blocked with either $1 \%$ BSA or $4 \%$ FBS in PBS. Samples were labeled with the indicated primary antibodies overnight at $4{ }^{\circ} \mathrm{C}$ in the presence of $0.01 \%$ saponin and blocking agents. Endogenous CD11b and p47phox were detected using specific mouse monoclonal antibodies, and endogenous $\mathrm{p} 67^{\text {phox }}$ and $\mathrm{p} 22^{\text {phox }}$ were detected using specific rabbit polyclonal antibodies and the appropriate combinations of Alexa Fluor (488 or 594) conjugated donkey anti-rabbit or anti-mouse secondary antibodies (Molecular Probes, Carlsbad, Calif., USA). In order to stain the extracellular traps, samples were incubated with $4^{\prime}, 6$ diamidino-2-phenylindole, dihydrochloride (DAPI) for $15 \mathrm{~min}$ at $21^{\circ} \mathrm{C}$ and washed with PBS. Cells were stored in Fluoromount-G (Southern Biotechnology, Birmingham, Ala., USA) and analyzed using a Bio-Rad (Zeiss) Radiance 2100 Rainbow laser scanning confocal microscopy attached to a Nikon TE2000-U microscope at $21^{\circ} \mathrm{C}$ with a $60 \times$ oil Plan-Apo $1.4 \mathrm{NA}$ objective. For visualization, fluorescence associated with Alexa Fluor 594-labeled secondary antibody was excited using the $543-\mathrm{nm}$ laser line and col- 
lected using a standard Texas Red filter. Fluorescence associated with Alexa Fluor 488-labeled secondary antibodies was visualized using the 488-nm laser line and collected using a standard FITC filter set. Images were collected using Bio-Rad Laser Sharp 2000 (version 3.2) software and processed using ImageJ and Adobe Photoshop CS.

\section{Detection of ROS Production}

ROS production measured by a luminol (or isoluminol)-dependent chemiluminescence assay using whole cells was carried out as previously described [19], except that exogenous peroxidase was omitted and luminescence was measured based on endogenous MPO activity. Briefly, $1 \times 10^{6}$ human neutrophils resuspended in RPMI medium in a final volume of $0.25 \mathrm{ml}$ were placed in a 96-well microtiter plate, warmed to $37^{\circ} \mathrm{C}$, and luminol was added to reach a final concentration of $100 \mu \mathrm{M}$ (DMSO final concentration was $0.1 \%$ ). The cells were stimulated with heat-killed opsonized or non-opsonized Escherichia coli or L. monocytogenes (InvivoGen, San Diego, Calif., USA) in the presence or absence of $100 \mathrm{U} / \mathrm{ml}$ protease- and RNase-free DNase I (Worthington, Lakewood, N.J., USA). In some experiments, cells were stimulated with PMA $(1 \mu \mathrm{g} / \mathrm{ml})$. Other assays were performed using HL-60 cells differentiated to granulocytes using 1.3\% DMSO as described [18]. Where indicated, the cell-impermeant isoluminol was used instead of luminol in the assays. Chemiluminescence was measured at 1 -min intervals for up to $210 \mathrm{~min}$ at $37^{\circ} \mathrm{C}$ using a Luminoskan luminometer (Labsystems Research, Helsinki, Finland).

\section{Phagocytosis Assay}

Phagocytosis was measured using the Vybrant Phagocytosis Assay Kit (Invitrogen, Carlsbad, Calif., USA) following manufacturer's instructions. Briefly, $1 \times 10^{5}$ human neutrophils were resuspended in a final volume of $0.15 \mathrm{ml} \mathrm{RPMI}$ and placed in a 96well microtiter plate. The cells were incubated in the presence of DNase I $(100 \mathrm{U} / \mathrm{ml})$ or cytochalasin D $(5 \mu \mathrm{g} / \mathrm{ml})$ for $15 \mathrm{~min}$ at $37^{\circ} \mathrm{C}$ or left untreated. Then, neutrophils were exposed to fluorescent E. coli BioParticles for $2 \mathrm{~h}$ at $37^{\circ} \mathrm{C}$. Non-phagocytosed fluorescent bacteria were quenched using Trypan blue. Samples were analyzed for fluorescence intensity (480 nm excitation/520 nm emission) using a SpectraMax Gemini EM spectrofluorometer (Molecular Devices, Sunnyvale, Calif., USA).

\section{Quantification of NETs Using a Nucleic Acid Stain}

Human neutrophils were seeded into 96-well plates $\left(1 \times 10^{5}\right)$ well) and stimulated with non-opsonized or opsonized $E$. coli or HKLM $\left(1 \times 10^{8} / \mathrm{ml}\right)$ in the presence or absence of DNase I $(100$ $\mathrm{U} / \mathrm{ml}$ ) for $1 \mathrm{~h}$ at $37^{\circ} \mathrm{C}$. In some experiments, the cells were stimulated with PMA for up to $60 \mathrm{~min}$ at $37^{\circ} \mathrm{C}$. Then, the cell-impermeable nucleic acid stain Sytox Green (Invitrogen) was added to a final concentration of $5 \mu \mathrm{M}$. Nonstimulated neutrophils were used as controls. The samples were analyzed for fluorescence intensity (485 $\mathrm{nm}$ excitation/527 $\mathrm{nm}$ emission) using a SpectraMax Gemini EM spectrofluorometer (Molecular Devices).

\section{Experimental Animal Models}

Our experiments utilize ashen mice $\left(\mathrm{C} 3 \mathrm{H} / \mathrm{HeSn}-\mathrm{Rab} 27 \mathrm{a}^{\text {ash }}\right)$ that contain a splicing mutation in Rab27a and parental strains $\mathrm{C} 3 \mathrm{H} / \mathrm{HeSnJ}$. Ashen mice were extensively utilized for the study of Rab27a deficiency and were described previously [20].
Cell-Free Recombinant System and MPO Assay

The cell-free recombinant system using purified cytochrome $b_{558}$ was performed as previously described [21]. MPO activity was measured using the InnoZyme ${ }^{\mathrm{TM}} \mathrm{MPO}$ Activity Kit (EMB, San Diego, Calif., USA) following the manufacturer's recommendations.

\section{Transmission Electron Microscopy}

Human neutrophils $\left(2 \times 10^{6}\right)$ in RPMI were seeded in untreated, glass-bottom (No. 1.5 coverglass), 35-mm culture dishes (MatTek, Ashland, Mass., USA). Cells were treated with PMA or LPS for $90 \mathrm{~min}$ at $37^{\circ} \mathrm{C}$, and then processed for transmission electron microscopy. The samples were fixed in $2.5 \%$ glutaraldehyde in $0.1 \mathrm{M} \mathrm{Na}$ cacodylate buffer ( $\mathrm{pH} 7.3$ ), and then washed and fixed in $1 \%$ osmium tetroxide in $0.1 \mathrm{M} \mathrm{Na}$ cacodylate buffer. They were subsequently treated with $0.5 \%$ tannic acid followed by $1 \%$ sodium sulfate, and during the next buffer wash, any large, thick strands of NETs were removed and placed in microfuge tubes for separate processing as pellets. The fine network of NETs visible under the dissecting microscope immediately above the cells was left undisturbed. The coverslips and pellets were dehydrated in graded ethanols, and then, the coverslips were incubated in HPMA (Ladd Research, Williston, Vt., USA). Beem capsules filled with LX112 resin were inverted onto the coverslip to be polymerized overnight at $60^{\circ} \mathrm{C}$. The beem capsules were snapped off from the coverslip, and the terminal $2 \mathrm{~mm}$ of the resin block were cut off using a hacksaw to produce a resin disk, the lateral margins of which were trimmed using a Dremel. This resin disk, which contained the cells and NETs, was re-embedded flat so that thin transverse sections could be taken of the samples to effectively show a profile of attachment and any NETs associated with the 'apical surfaces' of the neutrophils. The pellets were treated with propylene oxide and embedded in Epon/Araldite. Thin sections $(70 \mathrm{~nm})$ of both the flat and pelleted samples were cut on a Reichert Ultracut E (Leica, Deerfield, Ill., USA) using a diamond knife (Diatome, Electron Microscopy Sciences, Hatfield, Pa., USA), mounted on parlodion-coated copper slot grids and stained in uranyl acetate and lead citrate. Sections were examined on a Philips CM100 TEM (FEI, Hillsbrough, Oreg., USA) and documented on Kodak SO-163 film for later analysis. Negatives were scanned at 600 lpi using a Fuji Fine Scan 2750XL and then converted to tiff format for subsequent handling in Adobe Photoshop.

\section{Results}

\section{DNase I Treatment Inhibits a Late Phase of ROS Production}

MPO, a heme enzyme that utilizes NADPH oxidasederived ROS to produce microbicidal oxidants, localizes on NETs [4]. We hypothesized that if MPO-derived ROS are produced on NETs, NET-associated ROS production would be impaired by treatment with DNase I. To test this hypothesis, we analyzed the ability of human neutrophils to generate ROS in the presence of RNase- and proteasefree DNase I. We first analyzed ROS production using the cell-permeant luminol, which detects both extracellular 
and intracellular ROS. Luminol-dependent chemiluminescence is indicative of the global oxidative response as luminol reacts with both $\mathrm{H}_{2} \mathrm{O}_{2}$ and hypochlorous acid (HOCl) $[22,23]$. Although luminol is not specific for a particular ROS, it constitutes a sensitive probe to determine the overall oxidative response in real time. Furthermore, luminol and isoluminol kinetics were measured in the absence of exogenous peroxidase so that they reflect the activity of endogenous MPO. In figure 1, we show that DNase I treatment attenuates the production of ROS by neutrophils. Neutrophils stimulated with either heatkilled opsonized Gram-negative E. coli or Gram-positive L. monocytogenes showed monophasic kinetics of ROS production peaking around $60 \mathrm{~min}$ after addition of the stimuli (fig. 1a, b). In the presence of DNase I at a concentration that abolishes the formation of NETs, maximal chemiluminescence levels were significantly decreased. Interestingly, the initial rate of ROS production in the presence of DNase I was indistinguishable from the control without DNase I up to 30 min after stimulation. Conversely, late-phase ROS production was significantly lower in the presence of DNase I when compared with that detected in conditions that maintain intact extracellular traps (fig. 1a, b). These data suggest that a late phase of the oxidative response to E. coli and L. monocytogenes is, in part, dependent on NET formation. Since luminol detects both intracellular and extracellular ROS [23], our results suggest that ROS production is bimodal, and only the second, presumably NET-associated, phase production of ROS is DNase sensitive. In companion experiments, we confirmed that neutrophils exposed to Grampositive or Gram-negative bacteria synthesize extracellular traps (fig. 1c). Non-opsonized bacteria were more effective than opsonized bacteria in inducing NETs, suggesting a possible cross-regulation between phagocytosis and extracellular trap formation. Importantly, although L. monocytogenes and E. coli are phagocy tosed by neutrophils and stimulate intraphagosomal as well as extracellular ROS production (see below), the phagocytic process was not affected by DNase I treatment when evaluated $2 \mathrm{~h}$ after bacterial exposure (fig. 1d), supporting the idea that DNase I affects extracellular but not intracellular ROS production. However, a possible effect of DNase I on early stages of phagosome maturation was not evaluated and cannot be ruled out under the experimental conditions used in this study.

The production of ROS in response to PMA, a phorbol ester that stimulates non-phagosomal oxygen radical production $[24,25]$, was also attenuated by DNase I (fig. 1e). We found the oxidative response to PMA to be biphasic when followed for periods over $30 \mathrm{~min}$. We also found that the second, but not the first, PMA-induced oxidative phase was significantly impaired by DNase I treatment (fig. 1e). The kinetics of NET formation in response to PMA, as measured by means of the membraneimpermeant DNA-binding probe Sytox Green, correlates with the second phase of ROS production (fig. 1f), sug-

Fig. 1. a, b ROS production is attenuated by DNase I. Human neutrophils were stimulated with opsonized E. coli (a) or HKLM (b) in the presence or absence of $100 \mathrm{U} / \mathrm{ml}$ DNase I. ROS production was measured as luminol-dependent chemiluminescence as described in Materials and Methods. Kinetic results are the mean \pm SEM of 1 representative experiment performed in triplicate (left panels). Unstimulated samples showed no significant luminescence (data not shown). The right panels show the maximum chemiluminescence at the indicated time. Results are the mean \pm SEM of 3 independent experiments with samples from different donors. Maximum chemiluminescence in samples treated with DNase I at $75 \mathrm{~min}$ but not at $30 \mathrm{~min}$ was significantly different from control ( $\left.{ }^{*} \mathrm{p}<0.05\right)$. c E. coli and L. monocytogenes stimulate NET formation. Human neutrophils were seeded into 96well plates and stimulated with non-opsonized heat-killed E. coli or HKLM or with the same bacteria previously opsonized with autologous serum (Ops.). Experiments were carried out in the absence (grey columns) or in the presence (white columns) of 100 $\mathrm{U} / \mathrm{ml}$ DNase I for $1 \mathrm{~h}$ at $37^{\circ} \mathrm{C}$. Next, the non-cell-permeant DNAbinding dye Sytox Green was added to a final concentration of $5 \mu \mathrm{M}$, and NET formation was evaluated fluorometrically with a setting of $485 \mathrm{~nm}$ (excitation) and $527 \mathrm{~nm}$ (emission). Cells incubated in the absence of bacteria and DNase I were used as control (C). d Phagocytosis in the presence of DNase I (100 U/ml) or cytochalasin D (Cyto D) was measured using fluorescently labeled E. coli as described in Materials and Methods. e Luminol-dependent chemiluminescence in response to PMA was monitored for $2 \mathrm{~h}$ in DNase-I-treated or -untreated human neutrophils. Kinetic results are the mean \pm SEM of 3 independent experiments, each of them performed in duplicate or triplicate. The right panel shows the maximum chemiluminescence at the indicated times. Results are the mean \pm SEM of 3 independent experiments with samples from different donors. ${ }^{*} \mathrm{p}<0.05$. $\mathbf{f}$ The kinetics of NET formation in response to PMA stimulation was followed using Sytox Green as described above. g ROS production by HL- 60 cells differentiated to granulocytes was monitored by luminol-dependent chemiluminescence after preincubation in the absence or presence of $100 \mathrm{U} / \mathrm{ml}$ DNase I. The cells were preincubated in the absence or presence of LPS $(100 \mathrm{ng} / \mathrm{ml})$ and stimulated with $1 \mu \mathrm{M}$ fMLF. Data are represented as the mean \pm SD from duplicate wells. h Isoluminol, a cell-impermeant analog of luminol, was used to analyze the effect of DNase I on opsonized HKLM-induced extracellular chemiluminescence. Circles indicate the basal luminescence level in the absence of HKLM. Results are represented as the mean \pm SD of duplicates from 1 experiment representative of 2 experiments with similar results. RFU = Relative fluorescence unit; RLU = relative light unit. 


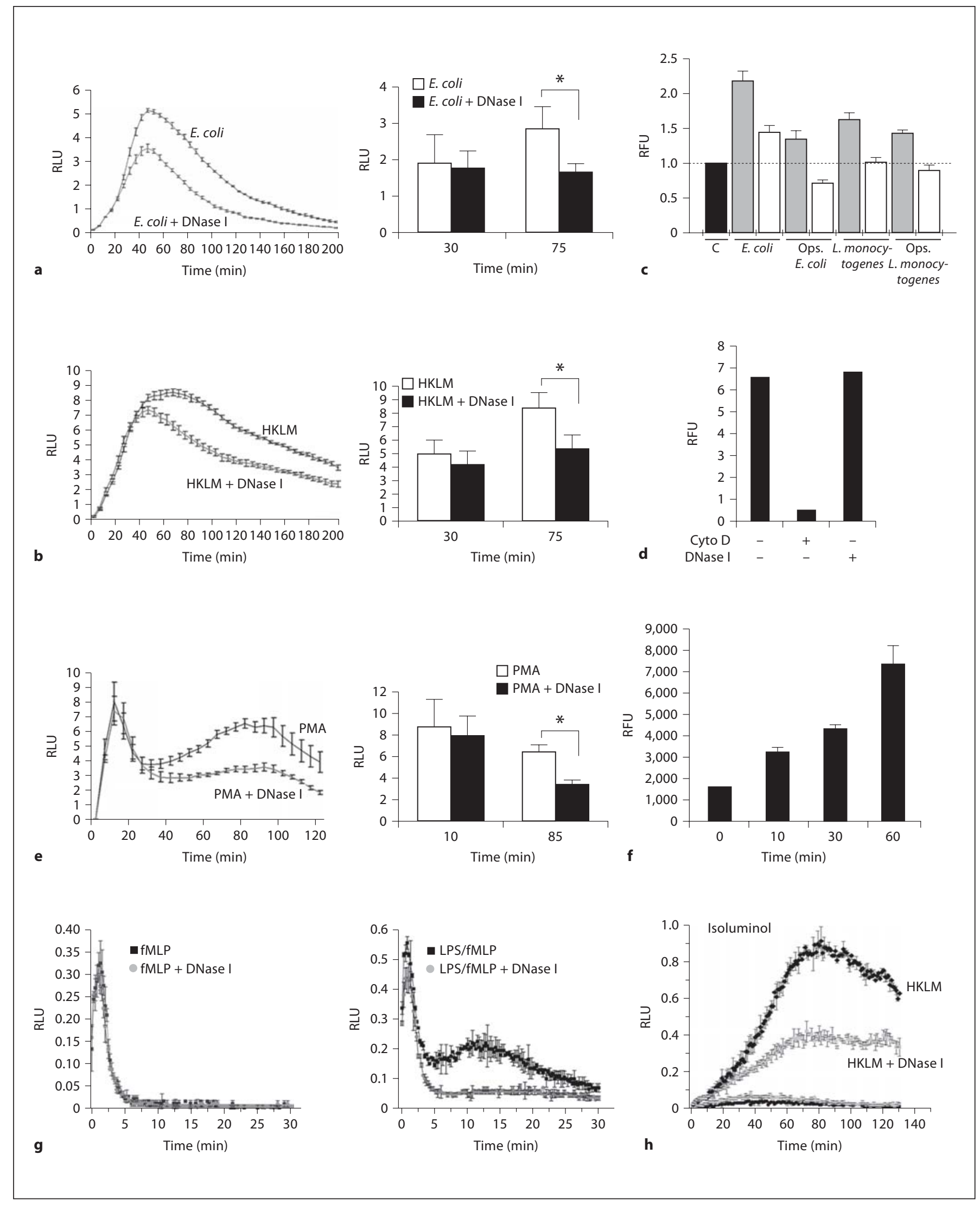


gesting time coordination between extracellular trap generation and the DNase-sensitive oxidative response. DNase-I-dependent inhibition of a late ROS production phase was also observed in HL-60 cells, recently shown to form extracellular traps [26]. The effect was not observed in fMLF-stimulated cells but was evident in cells that were primed with LPS and then stimulated with the chemotactic peptide (fig. 1g). NET formation in HL-60 cells under these experimental conditions was confirmed by immunofluorescence analysis (online suppl. fig. 1, www.karger.com/doi/10.1159/000235860). However, we noticed that neutrophils stimulated with phorbol ester form NETs more efficiently than HL-60 granulocytes. As HL-60 cells lack specific granules and ROS production in these cells is mainly extracellular, our results support the view that DNase I inhibits an extracellular mechanism of ROS generation. This is further manifested in companion studies using isoluminol, a membrane-impermeant analog of luminol that detects extracellular ROS. In figure $1 \mathrm{~h}$, we show that isoluminol-dependent chemiluminescence elicited by opsonized L. monocytogenes-stimulated neutrophils is inhibited by DNase I. Similar results were observed when E. coli was used instead of the Grampositive bacterium (data not shown). Altogether, our results support the idea that DNase I interferes with an extracellular late phase of ROS production. Importantly, the effect is independent of cell viability since DNase I treatment did not affect neutrophil viability as evaluated by Trypan blue exclusion (online suppl. fig. 2).

\section{The Inhibitory Effect of DNase I on ROS Production}

Is Independent of Actin Depolymerization and

Phagocytosis

In vitro, DNase I depolymerizes F-actin and binds to G-actin [27]. Although in our experiments we use intact cells and internalization of DNase I has not been shown, to rule out a possible inhibitory effect of DNase I on ROS production through a mechanism that involves interaction with the actin cytoskeleton, we performed experiments in the presence of cytochalasin $\mathrm{D}$, an agent that caps the barbed ends of F-actin [28], inhibits actin polymerization and induces depolymerization of actin filaments [29]. Here, we show that in the presence of cytochalasin $\mathrm{D}$, the neutrophil oxidative response to non-opsonized HKLM is increased even in the presence of DNase I (fig. 2a, b). The cytochalasin-D-mediated amplification of the chemiluminescence response is most likely explained by the already known effect of actin depolymerization on neutrophil granule mobilization which increases the number of NADPH oxidase subunits at the plasma membrane and the extracellular availability of MPO, thus increasing extracellular ROS production. However, in the presence of DNase I, the oxidative response was significantly reduced when compared with the non-DNase I control either in the absence or presence of cytochalasin D (fig. 2a, b), suggesting that the mechanism mediated by DNase I is independent of a putative interaction with actin. Interestingly, after treatment with cytochalasin D, the inhibitory effect of DNase I on the neutrophil oxidative response was observed as early as 15 min after the addition of the stimulus (fig. $2 b, d$ ). This is probably explained by the increased availability of extracellular MPO after cytochalasin D treatment and the consequent faster assembly of granular proteins on NETs.

Cytochalasin $\mathrm{D}$ is a potent inhibitor of phagocytosis [30]. In the absence of cytochalasin D, the oxidative response to opsonized bacteria was significantly larger than the response to non-opsonized microorganisms (fig. 2a, c), probably reflecting the more efficient mechanism of phagocytosis and neutrophil intraphagosomal ROS production for opsonized bacteria. Importantly, DNase I treatment inhibited ROS production to a similar extent whether or not phagocytosis was blocked by cytochalasin $\mathrm{D}$. These results suggest that the mechanism mediating DNase-I-dependent inhibition of ROS production is most likely extracellular. Furthermore, although non-opsonized bacteria seem more efficient than opsonized bacteria in triggering NET formation (fig. 1c), the observation that a larger proportion of the oxidative response is DNase I sensitive when opsonized bacteria are utilized as stimuli (fig. 2a, c) suggests that opsonized bacteria are more efficient in triggering a NET-associated oxidative response.

\section{MPO Localizes on NETs by a Mechanism That Is Independent of Exocytosis}

Elastase, a cargo protein from azurophilic granules, has been shown to localize on NETs [4]. MPO, another component from primary granules, has also been suggested to colocalize with NETs [4]. Here, we confirm, by immunofluorescence analysis, the presence of MPO on NETs (fig. 3a). These data, together with the observation that luminol-dependent chemiluminescence is attenuated by DNase treatment, suggest that MPO-derived oxidants are produced in association with NETs. Although MPO is detected in NETs, the mechanism that regulates the localization of granular proteins on extracellular DNA fibers remains to be elucidated. In this study, we evaluated whether neutrophils deficient in the small 


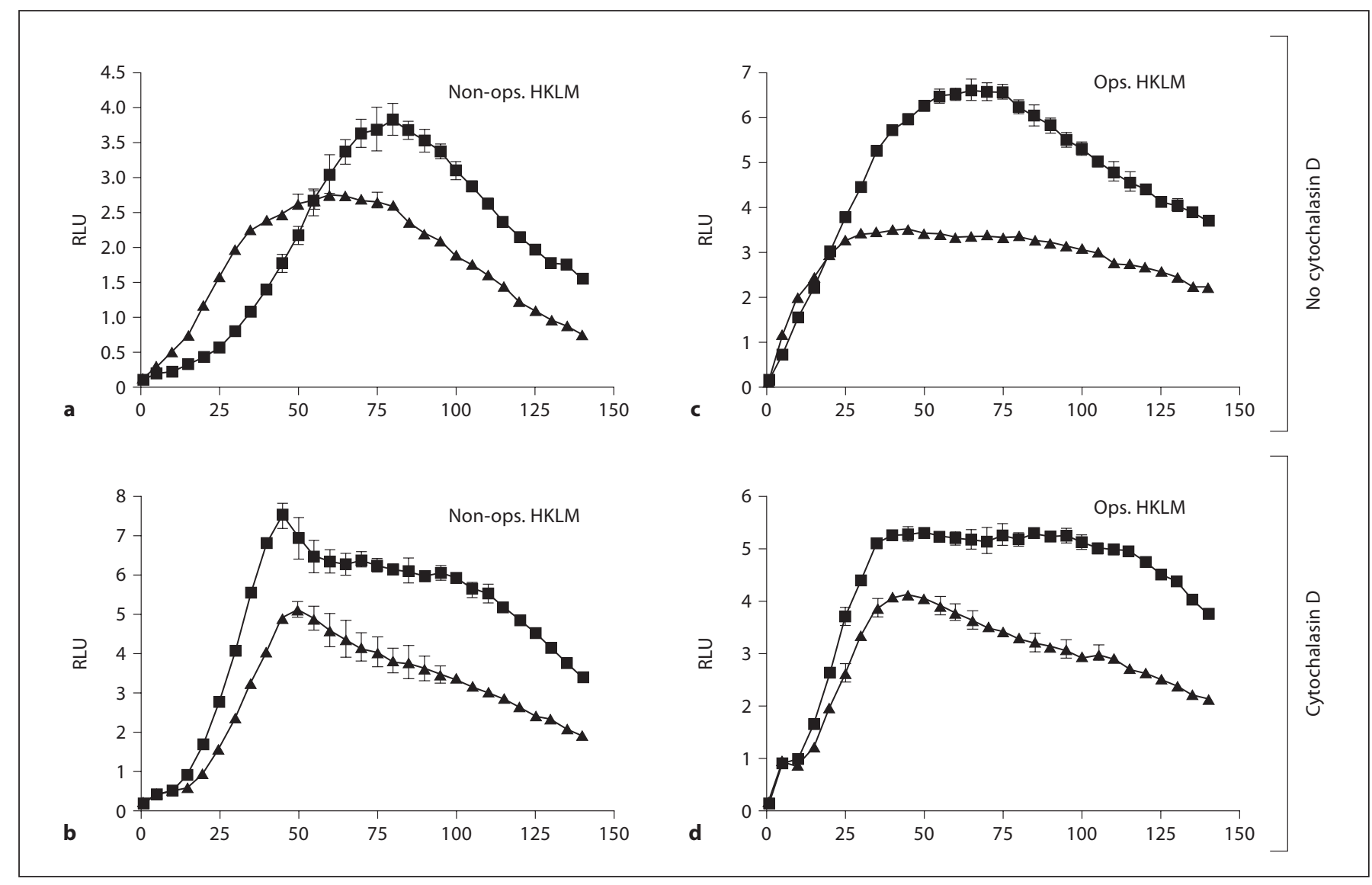

Fig. 2. The inhibitory effect of DNase I on ROS production is independent of actin depolymerization and phagocytosis. Human neutrophils were stimulated with non-opsonized (non-ops.; a, b) or opsonized (ops.; c, d) HKLM in the presence $(\boldsymbol{\Delta})$ or absence (ם) of $100 \mathrm{U} / \mathrm{ml}$ DNase I. ROS production was measured as luminol-dependent chemiluminescence as described in figure 1 except that, where indicated, cells where preincubated in the presence of $10 \mu \mathrm{g} / \mathrm{ml}$ cytochalasin D for $10 \mathrm{~min}$ before the addition of bacteria. Kinetic results are the mean \pm SD from 1 experiment representative of 2 independent experiments. Unstimulated samples showed no significant luminescence (data not shown). RLU = Relative light unit.
GTPase Rab27a, ashen [20], contain MPO on NETs. Rab27a is an essential component of the secretory machinery of azurophilic granules [18, 31]. MPO exocytosis is dramatically impaired in both human and murine neutrophils in the absence of Rab27a function, although MPO distribution and total MPO content are not significantly different in Rab27a-deficient neutrophils [18, 31] (data not shown). It was then interesting to evaluate whether protein distribution on NETs was dependent on Rab27a. In figure 3, we show, by immunofluorescence analysis, that Rab27a-deficient neutrophils form NETs and that MPO is detected in extracellular traps from ashen mice. These results suggest that exocytosis and granular protein distribution on NETs proceed by independent mechanisms.

\section{NADPH Oxidase Subunits Localize on NETs}

Next, we explored whether NADPH oxidase subunits are present in extracellular traps. Here, we established the presence of endogenous NADPH oxidase subunits in extracellular traps by fluorescence confocal microscopy. First, in figure $4 \mathrm{a}$, we show that $\mathrm{p} 22^{\text {phox }}$ is present in extracellular DNA fibers in fields where there is significant NET formation in neutrophils stimulated with phorbol ester. Next, we show that the cytosolic subunit p67phox and the membrane-associated subunit $\mathrm{p} 22^{p h o x}$ are present on extracellular traps formed by neutrophils stimulated with either LPS or with the heat-killed Gram-positive bacteria L. monocytogenes (fig. 4b). The organization of the NADPH oxidase in punctate structures resembles the distribution of globular domains of unknown origin described on 
Fig. 3. Localization of MPO on NETs in wild-type and Rab27a-deficient neutrophils. Neutrophils from wild-type (WT)

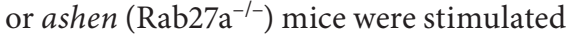
with PMA $(100 \mathrm{ng} / \mathrm{ml})$ for $60 \mathrm{~min}$, and MPO was detected on NETs by immunofluorescence confocal microscopy analysis as described in Materials and Methods. Upper and middle panels: MPO localization on NETs detected using the DNAbinding fluorescent probe DAPI in wild-type and Rab27a-deficient neutrophils. Lower panels: MPO staining in a cell that is not forming NETs is shown. Control antibodies do not recognize structures on NETs when used under the same experimental conditions. Scale bars $=5 \mu \mathrm{m}$.

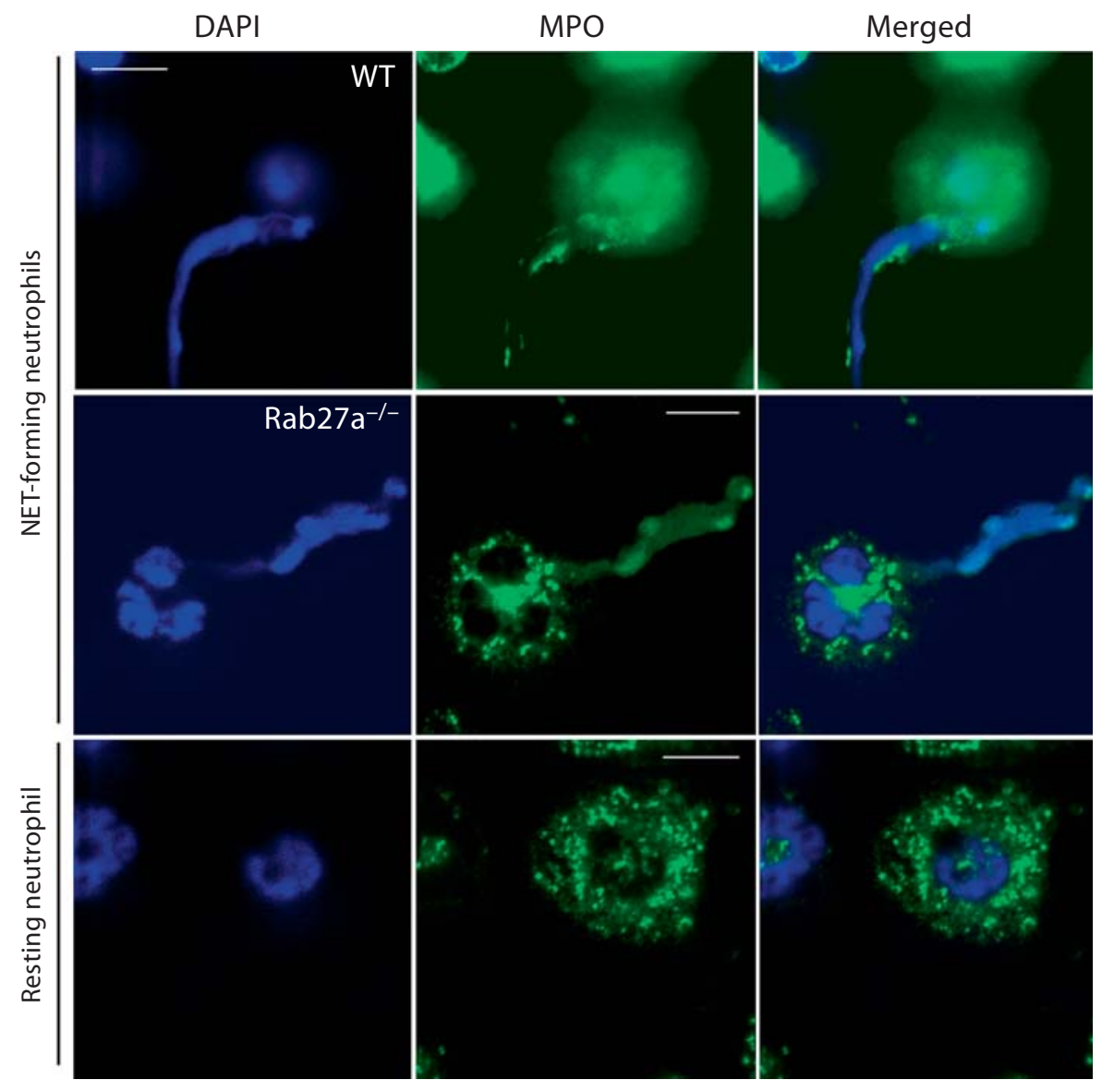

NETs [4]. The NADPH oxidase subunits were frequently detected in association with the membrane protein CD11b (fig. $4 \mathrm{~b}$ ), part of the $\beta_{2}$-integrin Mac-1 and a neutrophil ectosome marker [32]. No fluorescence was detected when irrelevant antibodies were used (fig. 4c). Another cytosolic subunit of the NADPH oxidase, p47 $7^{\text {phox }}$, was also detected in association with NETs (fig. 4d, e). Immunostaining using antibodies specific for the detection of $\mathrm{p} 47^{\text {phox }}$ and either $\mathrm{p} 22^{\text {phox }}$ or $\mathrm{p} 67^{\text {phox }}$ show that these proteins colocalize on punctate structures distributed on neutrophil traps (fig. $4 \mathrm{~d}, \mathrm{e}$ ). However, p $47^{\text {phox }}$ but not p22 $2^{\text {phox }}$ was also detected in non-globular structures, suggesting that it may too bind directly to DNA fibers through electrostatic interaction. Detection of extracellular, NET-associated NADPH oxidase subunits was abolished by treatment with DNase I (fig. 4e), a condition shown to disrupt extracellular traps when evaluated by fluorescence microscopy analysis. This supports the idea that the distribution of oxidase subunits in punctate extracellular structures requires the structural support provided by NETs.

\section{DNase I Does Not Directly Inhibit NADPH Oxidase or MPO Activity}

A previous study demonstrated that DNase I inhibits NADPH oxidase through F-actin depolymerization when evaluated in a cell-free system that utilizes neutrophil membranes as the source of cytochrome $b_{558}$ [33]. Here, to rule out a direct inhibitory effect of DNase I on NADPH oxidase activity, we utilized a very well characterized cellfree system that uses purified cytochrome $b_{558}$ in the absence of actin [21]. In these studies, we utilized 2 different sources of bovine pancreas recombinant DNase I [New England Biolab (DNase IA) and Worthington (DNase IB)]. Although we observed a minor decrease in the oxidase activity in the presence of DNase IA, the effect was nonspecific because the decreased activity also became apparent in the presence of buffer A but not in the presence of DNase IB or buffer B (fig. 5a). In any case, the differences were not statistically significant. In conclusion, the results presented in figure 5 a show that NADPH oxidase activity is not significantly affected by treatment 

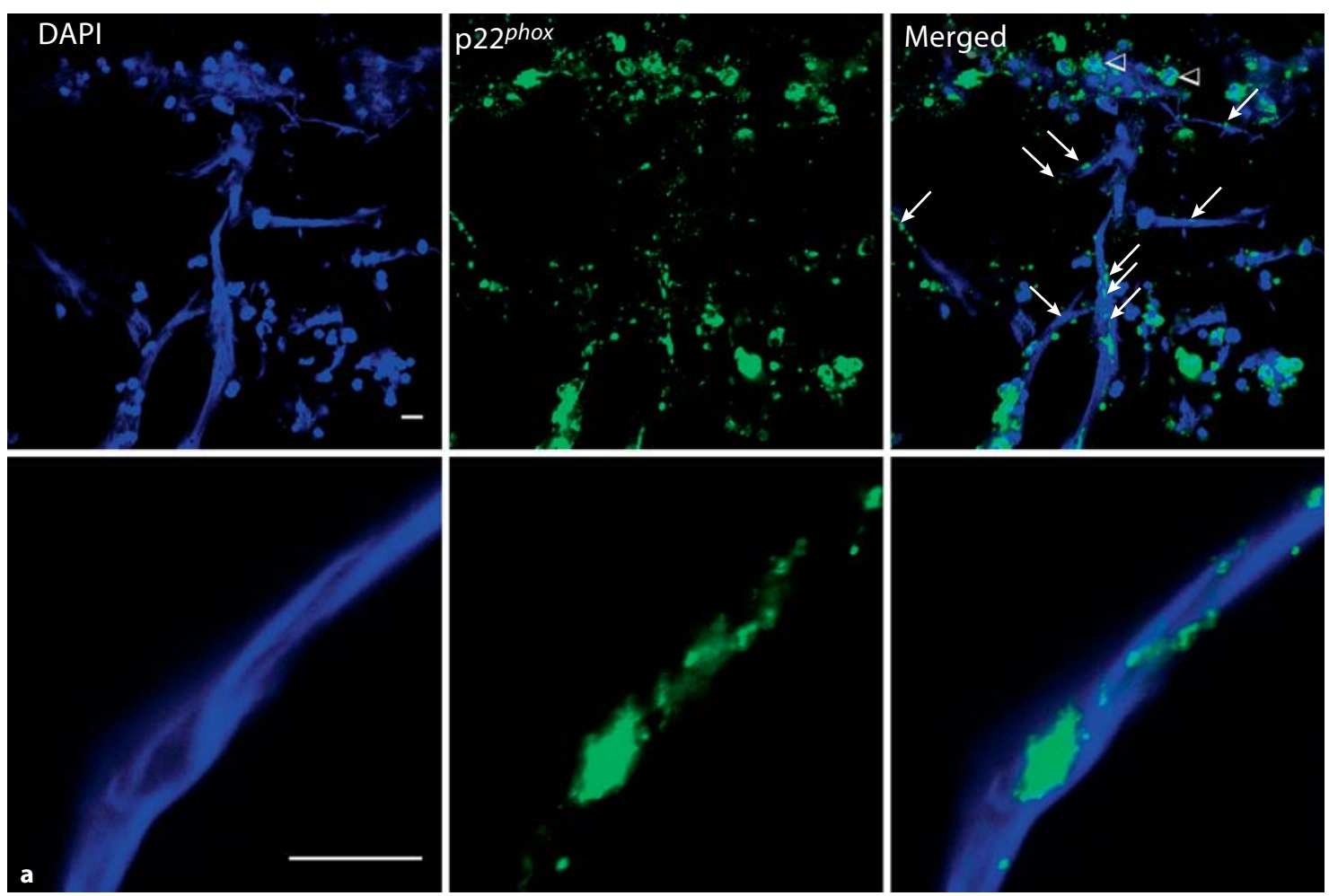

Fig. 4. Localization of NADPH oxidase subunits on NETs. Neutrophils were stimulated with PMA $(100 \mathrm{ng} / \mathrm{ml})$, LPS $(100 \mathrm{ng} / \mathrm{ml})$ or HKLM for $90 \mathrm{~min}$, and the NADPH oxidase subunits were detected on NETs by immunofluorescence confocal microscopy analysis as described in Materials and Methods. a Immunofluorescence analysis showing that $\mathrm{p} 22^{\text {phox }}$ is present on extracellular
DNA fibers in fields where there is significant NET formation in neutrophils stimulated with phorbol ester (upper panels). The lower panels show a higher magnification of a field where $\mathrm{p} 22^{\text {phox }}$ can be detected in punctate structures on NETs. Arrows indicate p22 phox -specific staining on NETs; arrowheads indicate p22 phox specific staining on intact neutrophils. Scale bars $=10 \mu \mathrm{m}$. with DNase I, thus ruling out a direct inhibitory effect of the enzyme on NADPH oxidase function. Next, to further explore the possible effect of DNase I on ROS production through MPO inhibition, we evaluated MPO activity in vitro after incubation in the presence or absence of DNase I. No significant differences in MPO activity were found between DNase-I-treated and -untreated samples (fig. 5b). Altogether, our results presented in figure 5 argue against a direct inhibitory effect of DNase on ROS production enzymes.

Transmission Electron Microscopy Shows the Presence of Trapped Neutrophils, Granules and Vesicular

Membrane in NETs

In order to identify a possible source of ROS to support MPO activity on NETs, we analyzed the ultrastructure of extracellular DNA fibers by transmission electron microscopy. First, we show that neutrophils stimulated with the Gram-negative bacteria-wall component LPS showed the ultrastructure characteristics of NETs (fig. 6). Similar to the description by Fuchs et al. [34], only a portion of LPS-stimulated cells showed the signature of NET formation (fig. 6a) supporting the idea that neutrophils not forming NETs could produce ROS to maintain NET-associated MPO activity. The nuclear envelope and condensed chromatin were not detected in cells producing NETs (fig. 6b), although partial preservation of the plasma membrane was observed (fig. 6b). Importantly, membrane vesicle structures and intact granules were frequently observed trapped in neutrophil extracellular DNA fibers (fig. 6c-e). Extracellular traps appeared as a filamentous material containing granular structures distributed homogenously on the fibers (fig. 6f). Analysis of cross-sections of NETs by transmission electron microscopy confirmed that the characteristic filamentous material is completely destroyed by treatment with DNase I 

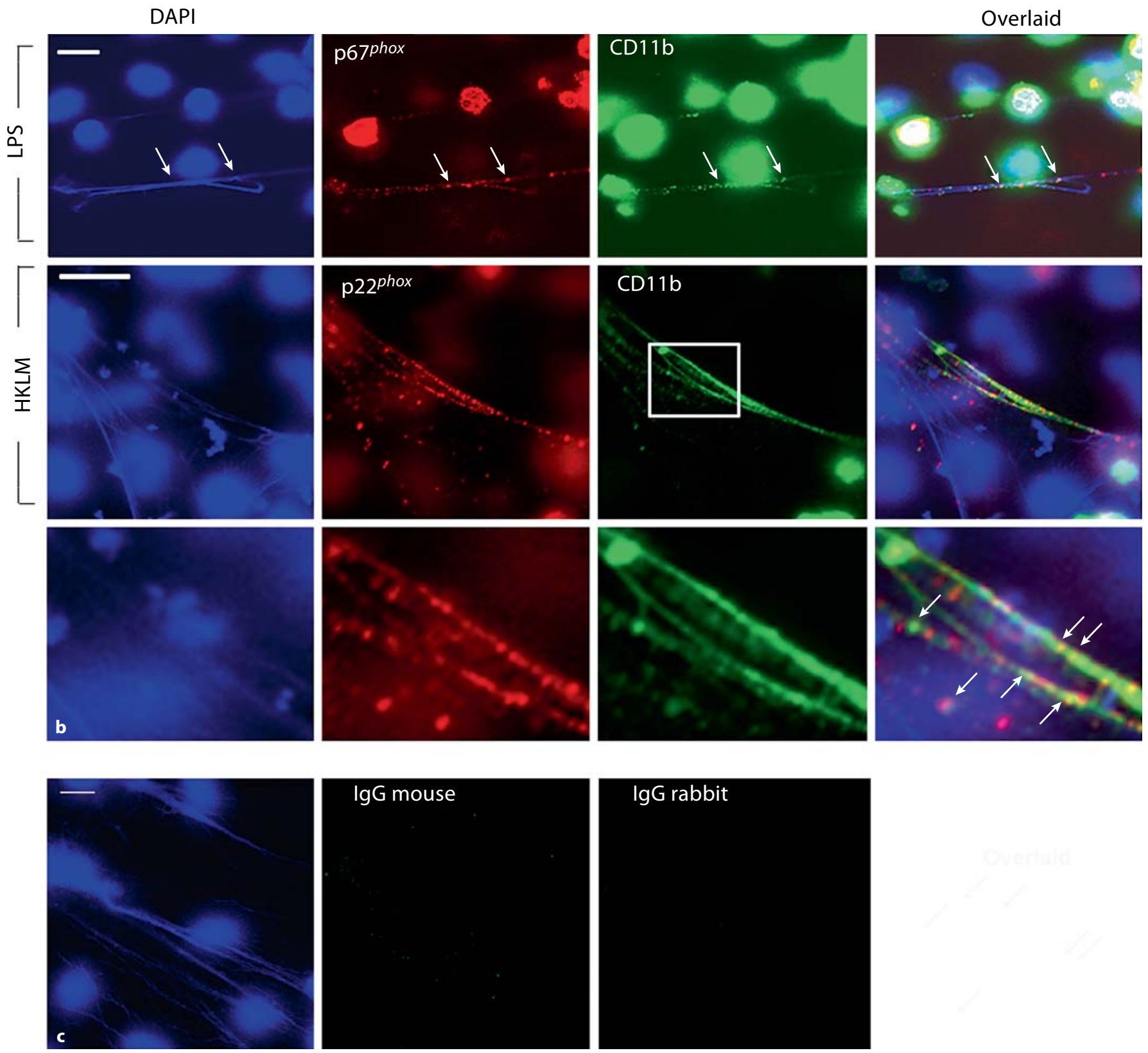

Fig. 4. Localization of NADPH oxidase subunits on NETs. Neutrophils were stimulated with PMA (100 ng/ml), LPS (100 ng/ml) or HKLM for $90 \mathrm{~min}$, and the NADPH oxidase subunits were detected on NETs by immunofluorescence confocal microscopy analysis as described in Materials and Methods. b The upper and middle panels show localization of $\mathrm{p} 67^{\text {phox }}$ and $\mathrm{p} 22^{\text {phox }}$, respectively, on NETs detected using DAPI. NADPH oxidase subunits were detected in close proximity to the ectosome marker CD11b. Some of these structures are indicated with arrows. The lower panels show the magnification of the area highlighted on the middle panels. Scale bars $=10 \mu \mathrm{m}$. c Control antibodies do not recog- nize structures on NETs when used under the same experimental conditions. Scale bar $=10 \mu \mathrm{m}$. d Immunofluorescence analysis shows that the cytosolic subunit $\mathrm{p} 47^{\text {phox }}$ and the cytochrome $b_{558}$ component $\mathrm{p} 22^{\text {phox }}$ colocalize on punctate structures distributed on NETs. Some of these structures are indicated with arrows. Neither NETs nor NADPH oxidase subunits were detected extracellularly in the absence of stimuli. Scale bars $=10 \mu \mathrm{m}$. e Immunofluorescence analysis of the distribution of NADPH oxidase subunits on NETs in neutrophils stimulated with $100 \mathrm{ng} /$ $\mathrm{ml}$ LPS for $90 \mathrm{~min}$ in the absence (upper panels) or presence (lower panels) of $100 \mathrm{U} / \mathrm{ml}$ DNase I. Scale bars $=10 \mu \mathrm{m}$. 

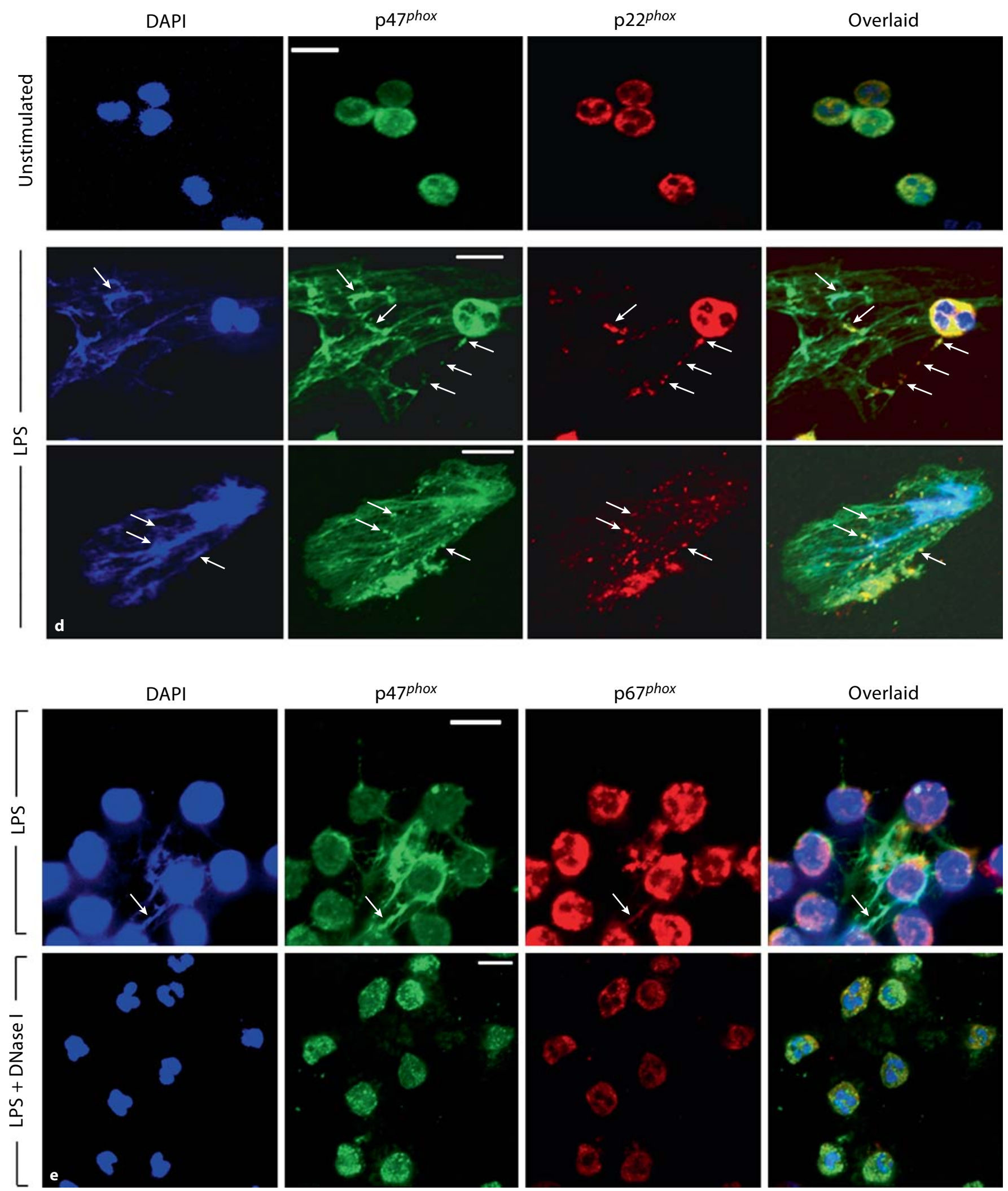

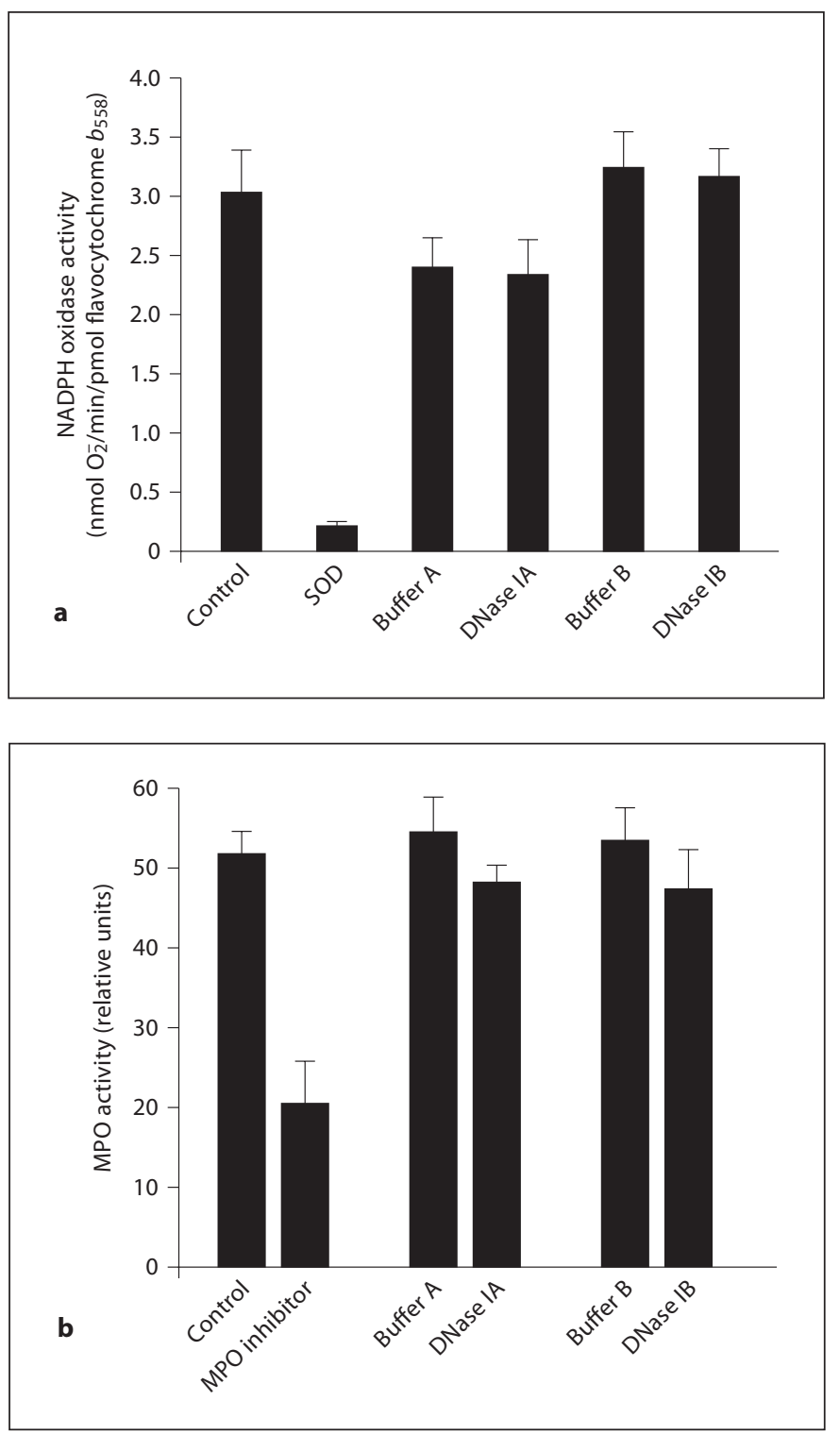

Fig. 5. Lack of inhibition of NADPH oxidase and MPO by DNase I treatment. a The NADPH oxidase total recombinant system was used to evaluate a possible effect of DNase I on the oxidase activity. To this end, recombinant proteins were incubated for 5 min to allow the assembly of the oxidase and were subsequently incubated in the presence of $100 \mathrm{U} / \mathrm{ml}$ DNase IA (New England Biolab) and DNase IB (Worthington) in their corresponding reaction buffers, in the absence of DNase I and DNase buffer (control) or in the presence of superoxide dismutase (SOD) for $10 \mathrm{~min}$ at $37^{\circ} \mathrm{C}$. The production of superoxide anion was continuously monitored by cytochrome $c$ reduction at $550 \mathrm{~nm}$. The results (mean $\pm \mathrm{SEM}$ ) are representative of 2 independent experiments performed in triplicates. b Human MPO $(60 \mathrm{ng} / \mathrm{ml})$ was incubated in the presence or absence of DNase I $(100 \mathrm{U} / \mathrm{ml})$ for $1 \mathrm{~h}$ at $37^{\circ} \mathrm{C}$. MPO activity was measured as described in Materials and Methods. The results are the mean \pm SEM of 3 independent experiments performed in triplicates. No significant differences were found between DNase-I-treated and -untreated samples. while extracellular vesicular membranes were observed even after DNase I treatment (fig. $6 \mathrm{~g}$, h). Similar to the suggestion by Brinkmann et al. [4], no morphological evidence of apoptosis was observed in neutrophils activated with LPS or PMA for up to $90 \mathrm{~min}$.

\section{Discussion}

NETs have been implicated in the microbicidal activity of neutrophils against Gram-negative bacteria, Grampositive bacteria $[4,5,35]$ and fungi [36]. Their importance in innate immune defense has been highlighted by the observations that NETs are abundant in human inflammatory processes including spontaneous human appendicitis [4] and pre-eclampsia [37]. Importantly, microorganisms that evade NETs by means of their intrinsic DNase activity exacerbate virulence in a mouse model of necrotizing fasciitis [5]. The mechanisms involved in NET-dependent microorganism killing are not well understood. Here, we show that interfering with NET assembly using DNase I attenuates neutrophil ROS production, suggesting that this is another possible mechanism that favors the escape of DNase-positive microorganisms from extracellular killing.

MPO, an enzyme contained in azurophilic granules, is involved in host defense mechanisms [15]. When deficient in humans and mice, the innate immune response is impaired [38, 39]. MPO utilizes the $\mathrm{H}_{2} \mathrm{O}_{2}$ generated by $\mathrm{O}_{2}^{-}$dismutation to produce the potent oxidant $\mathrm{HOCl}$. Superoxide also reacts with MPO [14] and with MPO products to generate intermediate compound products which have been associated with tyrosine peroxide formation [40] and involved in MPO-dependent killing of Staphylo-

Fig. 6. Transmission electron microscopy analysis of NETs. Human neutrophils were seeded in untreated $35-\mathrm{mm}$ culture dishes and treated with $100 \mathrm{ng} / \mathrm{ml}$ LPS (a-f) or PMA $(\mathbf{g}, \mathbf{h})$ for $90 \mathrm{~min}$ at $37^{\circ} \mathrm{C}$ and then processed for transmission electron microscopy as described in Materials and Methods. a The arrows indicate NETforming cells with undetectable nuclear envelope or condensed chromatin. b Magnification of the area selected in $\mathbf{a}$. The arrow shows partial preservation of the plasma membrane. c-f NETs usually contain vesicular membranes (arrowhead in e) and granular structures (arrow in e). d-f Magnifications of the areas selected in c-e, respectively. $\mathbf{f}$ Extracellular DNA fibers appear as a filamentous material (arrowheads) containing granular structures (arrows). g, h Analysis of cross-sections of NETs showing that the characteristic filamentous material adjacent to a PMAstimulated neutrophil $(\mathbf{g})$ is completely dismantled by treatment with DNase I (h). 

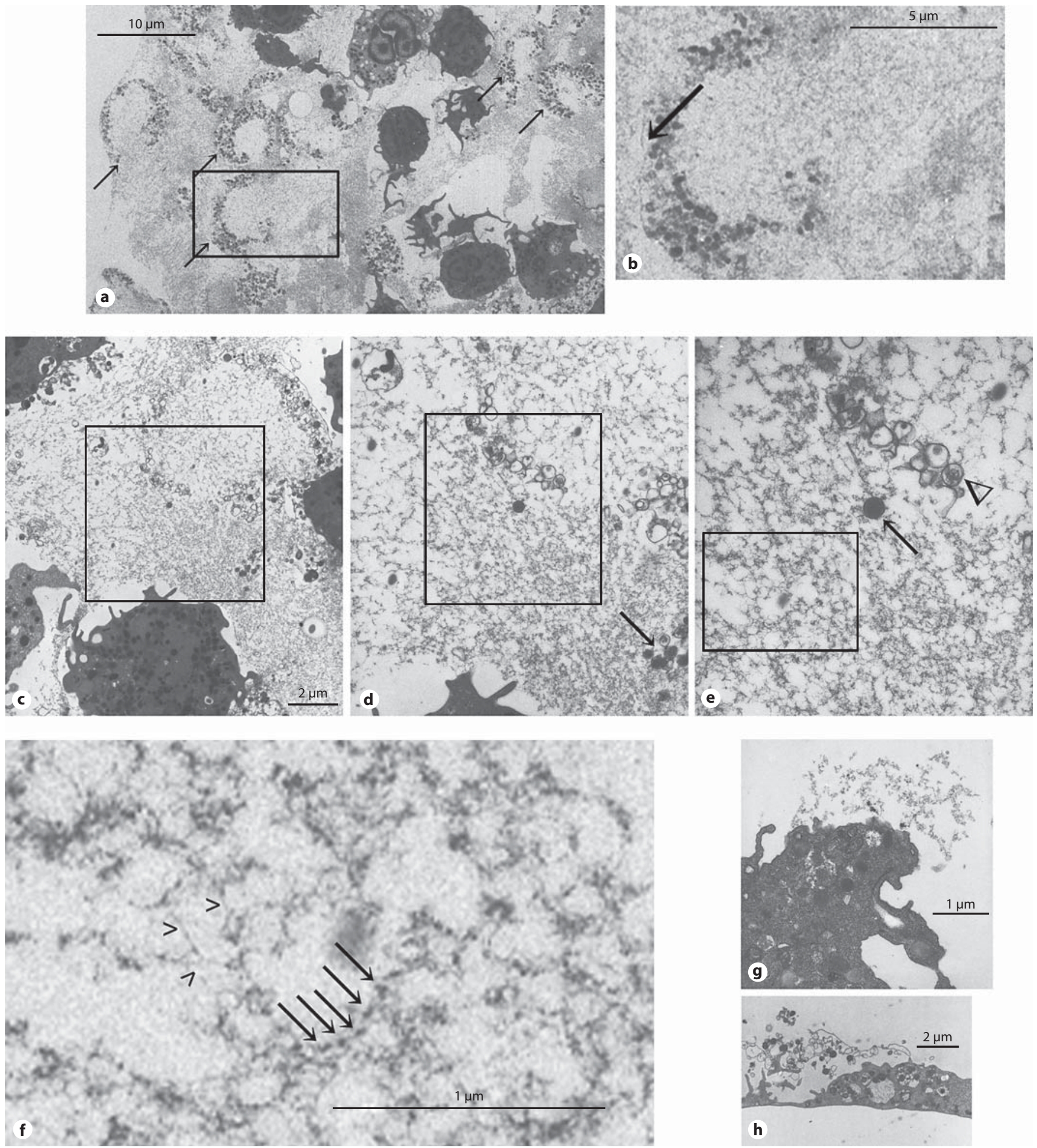
coccus aureus [41]. The microbicidal role of MPO was also attributed to the ability of its products to oxidize, iodinate and chlorinate target molecules in the invading microorganisms [15]. Recent studies confirmed that $\mathrm{HOCl}$ exerts its bactericidal effects via protein unfolding and aggregation [42]. Although $\mathrm{HOCl}$ has been shown to be formed inside the phagosome when neutrophils ingest bacteria [43], how neutrophils kill microorganisms in the extracellular milieu and the participation of MPO in this process is less clear. In support of a role for MPO in extracellular killing, previous studies showed that $\mathrm{HOCl}$ is produced extracellularly when neutrophils are stimulated with a variety of agonists [44]. It has also been suggested that the lower $\mathrm{pH}$ generally found at the site of infection and the lower extracellular enzyme concentration would favor halogenation reactions outside the cell [45], thus supporting the hypothesis that the MPO system has a microbicidal role in the extracellular milieu. In this study, we show that MPO localizes on NETs. Using luminol-dependent chemiluminescence, we also show that DNase I treatment is associated with decreased ROS levels. Although luminol detects both the intracellular and extracellular oxidative responses, we show that the inhibitory effect of DNase I was also manifested in cytochalasin-Dtreated cells, suggesting that it cannot be circumvented by induction of actin depolymerization or by inhibition of phagocytosis. Together with experiments using cellimpermeant isoluminol, these results suggest that the mechanism of DNase-I-mediated ROS inhibition is extracellular and mediated by a mechanism that is independent of the already known interaction between actin and DNase I. Furthermore, the inhibitory effect of DNase I on ROS production does not seem to be mediated by direct MPO inhibition but most likely by inducing extracellular trap disassembly. Altogether, these data suggest that NET-associated MPO-derived ROS may play a significant role in the bactericidal activity of neutrophils.

Previous studies have not found evidence of the presence of various cytosolic proteins at NETs despite the massive breakage of cellular membranes during extracellular trap formation [4]. Here, we present evidence that p $47^{\text {phox }}$ and p67phox 2 cytosolic subunits of the NADPH oxidase, localize on extracellular traps. However, it is possible that these factors are bound to the cytochrome $b_{558}$, the membrane component of oxidase, before traps are formed. In fact, NADPH oxidase and ROS production are known to be initiated immediately after stimulation, while extracellular trap formation is a relatively slower process [4]. Furthermore, NET formation has been shown to be dependent on NADPH oxidase activity [34], again indicating that NADPH oxidase assembly precedes extracellular trap maturation.

A relevant question is whether a membrane-associated protein, the cytochrome $b_{558}$, which requires a transmembrane potential to produce superoxide could be functional on NETs. Furthermore, a constant supply of NADPH is necessary to maintain NADPH oxidase activity to support the hypothesis that NET-associated NADPH oxidase is the source of the $\mathrm{H}_{2} \mathrm{O}_{2}$ substrate for MPO associated with DNA fibers. No experimental evidence so far supports such a hypothesis, and the presence of a functional NADPH oxidase on NETs is highly improbable. A more likely scenario is that $\mathrm{H}_{2} \mathrm{O}_{2}$, produced by the relatively large subpopulation of neutrophils that do not form NETs (fig. 4, 6) or $\mathrm{H}_{2} \mathrm{O}_{2}$ made by catalasenegative microorganisms, diffuses to reach extracellular trap-associated MPO serving as its substrate.

Globular structures of unknown origin have been described to be regularly distributed on NETs [4]. We observed that the oxidase subunits colocalize on punctate structures on extracellular trap fibers resembling the globular NET domains previously described. These domains also contain MPO, histones and neutrophil elastase [4]. MPO and elastase, 2 cargo proteins of azurophilic granules, are also present in neutrophil microvesicles called 'ectosomes' [32]. These small vesicles have the unusual characteristic of containing cargo proteins which are segregated in different secretory organelles in resting neutrophils [32]. Importantly, we observed that $\mathrm{CD} 11 \mathrm{~b}$, a membrane-associated protein which localizes on secretory vesicles, secondary and tertiary granules in unstimulated neutrophils, is distributed in punctate NET-associated structures. This indicates that, similar to what has been observed for neutrophil microvesicles, proteins from different secretory organelles converge on NET globular domains. Interestingly, CD11b was also detected in neutrophil ectosomes [32] and, although not shown in neutrophils, the NADPH oxidase has also been found in cell-derived microvesicles [46] raising the question whether ectosome-associated NADPH oxidase could be trapped on NETs. Supporting a possible interaction between microvesicles and NETs, it has been pointed out that the ectosomal membrane is negatively charged [32]; therefore, electrostatic interaction between microvesicles and the cationic histones present on NETs is very likely. Furthermore, neutrophil vesicular membranes and granules are usually trapped on NETs (fig. 6), thus contributing to the distribution of granular proteins in extracellular DNA fibers. Despite these observations, the mere presence of proteins on NET globular 
structures may not necessarily correlate with their biological activity. Future efforts directed at analyzing the catalytic activity of NET-associated proteins in isolated DNA fibers are necessary to clarify the mechanism of NET-dependent killing.

Another relevant question is if NET disassembly may lead to inhibition of a late phase of ROS production. MPO is a cationic protein proposed to bind to the negatively charged surface of microorganisms and react there with $\mathrm{H}_{2} \mathrm{O}_{2}$ to initiate oxidant formation in close proximity to the ingested microbe [15]. It was also proposed that MPO function may be favored when the enzyme is bound to a physiological matrix [47]. Moreover, MPO association with NETs would concentrate the enzyme in close proximity to neutrophils that did not release DNA fibers which are the most likely source of substrate for MPO. Thus, NET dismantling by DNase-mediated digestion would dissolve the MPO-supporting matrix and possibly decrease the efficiency of MPO catalytic activity.
The original work by Zychlinsky's group [4] indicated that NET formation plays an important role in host defense by restricting microorganisms to a circumscriptive hostile environment. This was highlighted by the finding that microorganisms expressing DNase I evade NET-dependent killing [5]. Our data presented here support the view that extracellular ROS contribute to the generation of this adverse milieu and might directly participate in the NET-dependent microbicidal mechanism neutrophils use to combat non-phagocytosed microorganisms. We also suggest that the inhibition of ROS production by microorganism-derived DNase would contribute to their ability to evade killing.

\section{Acknowledgements}

This study was supported by US Public Health Service Grants AI024227 and HL088256 to S.D.C. and by the Sam and Rose Stein Endowment Fund. The purified cytochrome $b_{558}$ was a gift from Dr. Cross A.R.

\section{References}

$\checkmark 1$ Reeves EP, Lu H, Jacobs HL, Messina CG, Bolsover S, Gabella G, Potma EO, Warley A, Roes J, Segal AW: Killing activity of neutrophils is mediated through activation of proteases by $\mathrm{K}^{+}$flux. Nature 2002;416:291-297.

2 Babior BM: NADPH oxidase. Curr Opin Immunol 2004;16:42-47.

-3 Urban CF, Lourido S, Zychlinsky A: How do microbes evade neutrophil killing? Cell Microbiol 2006;8:1687-1696.

4 Brinkmann V, Reichard U, Goosmann C, Fauler B, Uhlemann Y, Weiss DS, Weinrauch Y, Zychlinsky A: Neutrophil extracellular traps kill bacteria. Science 2004;303:15321535.

5 Buchanan JT, Simpson AJ, Aziz RK, Liu GY, Kristian SA, Kotb M, Feramisco J, Nizet V: DNase expression allows the pathogen group A Streptococcus to escape killing in neutrophil extracellular traps. Curr Biol 2006;16: 396-400.

- 6 Segal AW, Harper A, Garcia R, Jones OT, Cross AR: The nature and function of the microbicidal oxidase system of neutrophils. Bull Eur Physiopathol Respir 1981;17:187191.

7 Babior BM, Woodman RC: Chronic granulomatous disease. Semin Hematol 1990;27: 247-259.

8 Babior BM: Activation of the respiratory burst oxidase. Environ Health Perspect 1994. 102(suppl 10):53-56.

DeLeo FR, Allen LA, Apicella M, Nauseef
WM: NADPH oxidase activation and assem-
bly during phagocytosis. J Immunol 1999;
163:6732-6740.
Ago T, Nunoi H, Ito T, Sumimoto H: Mecha-
nism for phosphorylation-induced activa-
tion of the phagocyte NADPH oxidase pro-
tein p47(phox). Triple replacement of serines
303, 304, and 328 with aspartates disrupts
the SH3 domain-mediated intramolecular
interaction in p47(phox), thereby activating
the oxidase. J Biol Chem 1999;274:33644-
33653.

11 Allen LA, DeLeo FR, Gallois A, Toyoshima S, Suzuki K, Nauseef WM: Transient association of the nicotinamide adenine dinucleotide phosphate oxidase subunits p47phox and p67phox with phagosomes in neutrophils from patients with X-linked chronic granulomatous disease. Blood 1999;93:35213530.

12 DeLeo FR, Renee J, McCormick S, Nakamura $M$, Apicella M, Weiss JP, Nauseef WM: Neutrophils exposed to bacterial lipopolysaccharide upregulate NADPH oxidase assembly. J Clin Invest 1998;101:455-463.

13 Karlsson A, Dahlgren C: Assembly and activation of the neutrophil NADPH oxidase in granule membranes. Antioxid Redox Signal 2002;4:49-60.

14 Odajima T, Yamazaki I: Myeloneperoxidase of the leukocyte of normal blood. 3. The reaction of ferric myeloperoxidase with superoxide anion. Biochim Biophys Acta 1972; 284:355-359.
15 Klebanoff SJ: Myeloperoxidase: friend and foe. J Leukoc Biol 2005;77:598-625.

16 Markert M, Andrews PC, Babior BM: Measurement of $\mathrm{O}_{2}^{-}$production by human neutrophils. The preparation and assay of NADPH oxidase-containing particles from human neutrophils. Methods Enzymol 1984; 105:358-365.

17 Pacquelet S, Johnson JL, Ellis BA, Brzezinska AA, Lane WS, Munafo DB, Catz SD: Crosstalk between IRAK-4 and the NADPH oxidase. Biochem J 2007;403:451-461.

18 Munafo DB, Johnson JL, Ellis BA, Rutschmann S, Beutler B, Catz SD: Rab27a is a key component of the secretory machinery of azurophilic granules in granulocytes. Biochem J 2007;402:229-239.

19 Johnson JL, Park JW, Benna JE, Faust LP, Inanami $\mathrm{O}$, Babior BM: Activation of p47(phox), a cytosolic subunit of the leukocyte NADPH oxidase. Phosphorylation of ser-359 or ser-370 precedes phosphorylation at other sites and is required for activity. J Biol Chem 1998;273:35147-35152.

20 Wilson SM, Yip R, Swing DA, O’Sullivan TN, Zhang Y, Novak EK, Swank RT, Russell LB, Copeland NG, Jenkins NA: A mutation in Rab27a causes the vesicle transport defects observed in ashen mice. Proc Natl Acad Sci USA 2000;97:7933-7938.

21 Cross AR: p40(phox) participates in the activation of NADPH oxidase by increasing the affinity of p47(phox) for flavocytochrome b(558). Biochem J 2000;349:113-117. 
22 Brestel EP: Co-oxidation of luminol by hypochlorite and hydrogen peroxide implications for neutrophil chemiluminescence. Biochem Biophys Res Commun 1985;126:482-488.

$\checkmark 23$ Dahlgren C, Stendahl O: Role of myeloperoxidase in luminol-dependent chemiluminescence of polymorphonuclear leukocytes. Infect Immun 1983;39:736-741.

-24 Karlsson A, Nixon JB, McPhail LC: Phorbol myristate acetate induces neutrophil NADPH-oxidase activity by two separate signal transduction pathways: dependent or independent of phosphatidylinositol 3-kinase. J Leukoc Biol 2000;67:396-404.

-25 Brown GE, Stewart MQ, Liu H, Ha VL, Yaffe MB: A novel assay system implicates PtdIns(3,4)P(2), PtdIns(3)P, and PKC delta in intracellular production of reactive oxygen species by the NADPH oxidase. Mol Cell 2003;11:35-47.

-26 Wang Y, Li M, Stadler S, Correll S, Li P, Wang D, Hayama R, Leonelli L, Han H, Grigoryev SA, Allis CD, Coonrod SA: Histone hypercitrullination mediates chromatin decondensation and neutrophil extracellular trap formation. J Cell Biol 2009;184:205-213.

27 Hitchcock SE: Actin deoxyroboncuclease I interaction. Depolymerization and nucleotide exchange. J Biol Chem 1980;255:56685673.

28 Cooper JA: Effects of cytochalasin and phalloidin on actin. J Cell Biol 1987;105:14731478.

29 Casella JF, Flanagan MD, Lin S: Cytochalasin D inhibits actin polymerization and induces depolymerization of actin filaments formed during platelet shape change. Nature 1981;293:302-305.

-30 Tse SM, Furuya W, Gold E, Schreiber AD, Sandvig K, Inman RD, Grinstein S: Differential role of actin, clathrin, and dynamin in Fc gamma receptor-mediated endocytosis and phagocytosis. J Biol Chem 2003;278:33313338.
>31 Brzezinska AA, Johnson JL, Munafo DB, Crozat K, Beutler B, Kiosses WB, Ellis BA, Catz SD: The Rab27a effectors JFC1/Slp1 and Munc13-4 regulate exocytosis of neutrophil granules. Traffic 2008;9:2151-2164.

32 Gasser O, Hess C, Miot S, Deon C, Sanchez JC, Schifferli JA: Characterisation and properties of ectosomes released by human polymorphonuclear neutrophils. Exp Cell Res 2003;285:243-257.

33 Tamura M, Kanno M, Endo Y: Deactivation of neutrophil NADPH oxidase by actin-depolymerizing agents in a cell-free system. Biochem J 2000;349:369-375.

34 Fuchs TA, Abed U, Goosmann C, Hurwitz R, Schulze I, Wahn V, Weinrauch Y, Brinkmann V, Zychlinsky A: Novel cell death program leads to neutrophil extracellular traps. J Cell Biol 2007;176:231-241.

35 Beiter K, Wartha F, Albiger B, Normark S, Zychlinsky A, Henriques-Normark B: An endonuclease allows Streptococcus pneumoniae to escape from neutrophil extracellular traps. Curr Biol 2006;16:401-407.

-36 Urban CF, Reichard U, Brinkmann V, Zychlinsky A: Neutrophil extracellular traps capture and kill Candida albicans yeast and hyphal forms. Cell Microbiol 2006;8:668-676.

37 Gupta A, Hasler P, Gebhardt S, Holzgreve W, Hahn S: Occurrence of neutrophil extracellular DNA traps (NETs) in pre-eclampsia: a link with elevated levels of cell-free DNA? Ann NY Acad Sci 2006;1075:118-122.

38 Lehrer RI, Hanifin J, Cline MJ: Defective bactericidal activity in myeloperoxidase-deficient human neutrophils. Nature 1969;223: 78-79.
9 Aratani Y, Koyama H, Nyui S, Suzuki K, Kura F, Maeda N: Severe impairment in early host defense against Candida albicans in mice deficient in myeloperoxidase. Infect Immun 1999;67:1828-1836.

40 Winterbourn CC, Kettle AJ: Reactions of superoxide with myeloperoxidase and its products. Jpn J Infect Dis 2004;57:S31-S33.

$\checkmark 41$ Hampton MB, Kettle AJ, Winterbourn CC: Involvement of superoxide and myeloperoxidase in oxygen-dependent killing of Staphylococcus aureus by neutrophils. Infect Immun 1996;64:3512-3517.

42 Winter J, Ilbert M, Graf PC, Ozcelik D, Jakob $\mathrm{U}$ : Bleach activates a redox-regulated chaperone by oxidative protein unfolding. Cell 2008;135:691-701.

$\checkmark 43$ Chapman AL, Hampton MB, Senthilmohan R, Winterbourn CC, Kettle AJ: Chlorination of bacterial and neutrophil proteins during phagocytosis and killing of Staphylococcus aureus. J Biol Chem 2002;277:9757-9762.

44 Grisham MB, Jefferson MM, Melton DF, Thomas EL: Chlorination of endogenous amines by isolated neutrophils. Ammoniadependent bactericidal, cytotoxic, and cytolytic activities of the chloramines. J Biol Chem 1984;259:10404-10413.

$>45$ Segal AW: How neutrophils kill microbes. Annu Rev Immunol 2005;23:197-223.

46 Janiszewski M, Do Carmo AO, Pedro MA, Silva E, Knobel E, Laurindo FR: Platelet-derived exosomes of septic individuals possess proapoptotic NAD $(\mathrm{P}) \mathrm{H}$ oxidase activity: a novel vascular redox pathway. Crit Care Med 2004;32:818-825.

47 Astern JM, Pendergraft WF III, Falk RJ, Jennette JC, Schmaier AH, Mahdi F, Preston GA: Myeloperoxidase interacts with endothelial cell-surface cytokeratin 1 and modulates bradykinin production by the plasma kallikrein-kinin system. Am J Pathol 2007; 171:349-360. 